\title{
Entre émancipation et conversion. Dilemmes juifs en Hongrie dans la première moitié du XIX ${ }^{\mathrm{e}}$ siècle
}

\author{
Miklós Konrád
}

\section{Résumé}

Suite à un bref rappel de la situation des Juifs en Hongrie à l'ère du Vormärz, l'article expose les discours des contemporains - juifs et chrétiens - sur la conversion des juifs, présente les quelques informations statistiques disponibles au sujet du nombre et du profil social des Juifs convertis au cours de cette période, pour finalement dresser le portrait de quatre hommes, deux hommes d'affaires et deux intellectuels, convertis entre 1825 et 1848, en s'efforçant de montrer ce que les données statistiques sur le profil des convertis ne peuvent révéler : la complexité et la multiplicité simultanées des possibles motivations qui conduisirent les juifs de cette époque à abandonner la religion et la communauté juives.

\section{Abstract}

After a brief overview of the situation of Hungarian Jewry in the Vormärz period, the article summarizes the contemporary - Jewish and Gentile - discourses on Jewish conversion, gives some statistical information about the number and the social profile of the Jews who converted in this period, and finally portrays four men, two businessmen and two intellectuals, who converted between 1825 and 1848. It seeks to highlight what statistical data on the profile of converts cannot reveal : the complexity and the simultaneous multiplicity of the possible motivations that led Jews to leave the Jewish fold in this period.

Les vingt-cinq années précédant la révolution de 1848 constituèrent une période charnière de l'histoire hongroise. Alors que Vienne semblait tenir solidement les rênes du pouvoir politique, mais que simultanément le régime féodal hongrois multipliait les signes économiques et sociaux de son épuisement final, une jeune génération d'hommes politiques et d'intellectuels, d'origine noble pour la plupart, parvint en un temps record à se constituer en mouvement politique et élabora le programme d'une Hongrie radicalement nouvelle, libérale et bourgeoise ${ }^{1}$. 


\section{La situation des Juifs en Hongrie}

Pour les Juifs vivant sur le sol hongrois, ceci signifiait la promesse de leur émancipation politique, de la fin d'un régime juridique d'exception dont le poids s'était quelque peu allégé depuis l'Édit de Tolérance de Joseph II publié pour les Juifs de Hongrie le 31 mars 1783, mais qui demeurait par nature discriminatoire et oppressif. En sus des impôts nationaux et locaux, les Juifs devaient payer à l'État la taxe de tolérance établie par Marie-Thérèse et finalement abolie en 1846 et la taxe dite de protection aux propriétaires terriens leur ayant permis de s'installer sur leurs terres (le Schutzgeld). Par ailleurs ils demeuraient exclus des villes minières et de la moitié des villes royales libres, leur accès à la propriété étant limité ${ }^{2}$.

Quasiment vidée de sa population juive à la fin de l'occupation ottomane, la Hongrie fut repeuplée à partir du dernier tiers du XVII ${ }^{\mathrm{e}}$ siècle par une immigration juive d'abord occidentale, depuis Vienne, la Basse-Autriche, la Silésie, la Bohème et surtout la Moravie, puis orientale, avec un afflux devenant massif de Juifs de Galicie après l'annexion de ce territoire par la monarchie des Habsbourg à la faveur du premier partage de la Pologne en 1772. De 11621 personnes en 1735, la population juive de Hongrie passa à 80775 en 1787, 185075 en 1825 pour finalement compter autour de 350000 âmes en $1850^{3}$. D'après les calculs de László Varga, entre 1735 et le milieu du XIX ${ }^{\mathrm{e}}$ siècle, $52 \%$ des Juifs immigrés en Hongrie étaient originaires de la Galicie ${ }^{4}$. La majorité de la population juive, presque $60 \%$ en 1825, vivait en habitat très dispersé dans les comitats frontaliers de l'Autriche, de la Moravie et de Galicie ${ }^{5}$, mais au début des années 1840 on trouvait déjà 328 communautés juives de plus de cent âmes ${ }^{6}$. À Pest, qui à défaut d'être la capitale officielle du pays, représentait déjà le centre politique, économique et culturel, la population juive passa de 10 familles en 1786 à plus de 14280 personnes en $1848^{7}$. À cette date, la future Budapest, créée en 1873 par l'union des villes de Pest, de Buda et d'Óbuda, comptait 18265 Juifs, soit $13 \%$ de la population locale ${ }^{8}$.

À l'ère du Vormärz hongrois, soit dans les années 1825-1848, la société juive, fortement divisée selon l'origine - occidentale ou galicienne - de ses membres, entamait les premiers pas de sa transformation. Si l'énorme majorité de la population juive demeurait dans une situation précaire, on assista à cette époque à la montée en puissance d'une couche de commerçants et d'entrepreneurs enrichis grâce au boom économique engendré par les

2. Zsigmond Groszmann, A magyar zsidók V. Ferdinánd alatt (1835-1848), Budapest, Egyenlőség, 1916 ; László Simon, Zsidókérdés a magyar reformkorban (1790-1848), Debrecen, Bertók Lajos, 1936.

3. Alajos Kovács, A zsidóság térfoglalása Magyarországon, Budapest, 1922, p. 58-59. Pour précis qu'ils semblent être, ces chiffres n'étaient certainement pas exacts. Pour 1850, les calculs et estimations basés sur le recensement autrichien, fortement biaisé, vont de 328000 à 400000 personnes. Voir Elek Fényes, Az ausztriai birodalom statistikája és földrajzi leírása, Pest, Heckenast Gusztáv, 1857, p. 246 ; Dezső Dányi, Az 1850. és 1857. évi népszámlálás, Budapest, Központi Statisztikai Hivatal, 1993, p. 63 ; Michael K. Silber, « Hungary Before 1918 », dans The YIVO Encyclopedia of Jews in Eastern Europe, dir. Gershon David Hundert, New Haven/Londres, Yale University Press, 2008, 2 vol., t. I, p. 770-782, ici p. 771.

Les articles de l'encyclopédie peuvent être consultés sur le site http://www.yivoencyclopedia.org/

4. László Varga, «Zsidó bevándorlás Magyarországon », Századok, n 1, 1992, p. 59-79.

5. Ernô Marton, A magyar zsidóság családfája. Vázlat a magyarországi zsidók település-történetéhez, Kolozsvár, Fraternitas, 1941, p. 52.

6. Lajos Venetianer, A magyar zsidóság története a honfoglalástól a világháború kitöréséig, Budapest, Fôvárosi Nyomda Rt., 1922. p. 106-112.

7. József Kőrösi, Pest, szabad királyi város, az, 1870dik évben. À népszámlálás és népleírás eredményei, Pest, Ráth Mór, 1871, p. 37 ; id., « Buda és Ó-buda városa népességének évenkénti kimutatása 1813-tól 1857-ig », Statisztikai Havi Füzetek, n 5, 1881, p. 131-137, ici p. 136.

8. Ibid. 
guerres napoléoniennes. À leur tête on peut citer les familles Ullmann, Wodianer, Boskovitz, Goldberger, Kanitz ou Koppl ${ }^{9}$. L'époque est également marquée par l'arrivée sur scène des premiers intellectuels acculturés : journalistes, rédacteurs, parfois poètes et écrivains (de second rang). Ces intellectuels prennent part aux débats publics, sont germanophones pour la plupart, mais dans quelques rares cas, ils maitrisent déjà le hongrois ${ }^{10}$. C'est enfin l'époque des premières réformes du culte. À l'exception d'une brève flambée qui, avant et pendant la révolution de 1848, vit l'éclosion à Nagyvárad, Arad, Lugos, Pest, Nagybecskerek, puis Pécs, d'associations prônant des réformes radicales ${ }^{11}$, la réforme du judaïsme allemand pénétra en Hongrie à travers la médiation modératrice de ce qui devint connu sous le nom de rite viennois. Introduites d'abord à Pest en 1827 par l'homme d'affaires Gábor Ullmann, un des dirigeants de la communauté juive de Pest, elles ne furent officiellement reconnues par les autorités qu'en 1833. Ces réformes s'inspirèrent directement de celles réalisées quelques années plus tôt dans la capitale autrichienne par le Prediger Isaac Noah Mannheimer mais s'en tinrent pour l'essentiel à des innovations cosmétiques $^{12}$. Malgré la modération de ces réformes, ces années furent également celles de la naissance de l'antagonisme entre réformateurs et traditionalistes, entre d'un côté les partisans de la mise en conformité du judaïsme avec l'esprit des temps, et de l'autre ceux qui refusaient d'accommoder la foi juive, ses pratiques et son modèle éducatif traditionnel aux exigences de la société majoritaire. Phénomène unique en Europe, cet antagonisme conduira en 1869 à la scission des Juifs de Hongrie en trois branches juridiquement distinctes : les « néologues », les « orthodoxes », ces derniers eux-mêmes divisés entre une ultra-orthodoxie concentrée dans le nord-est du pays et une aile plus modérée avec Pozsony pour centre, et au milieu, pourrait-on dire, un certain nombre de communautés dites « statu quo ante », qui, désireuses de sauvegarder la structure autonome des communautés juives, refuseront de rejoindre l'une ou l'autre des organisations nationales avalisées par l'État ${ }^{13}$.

En dépit de ces changements, c'est là un point qu'il faut souligner, l'écrasante majorité de la population juive de Hongrie vit encore à l'époque du Vormärz dans le monde de la tradition : sa langue est majoritairement le yiddish, l'adoption du hongrois est lente. D'une manière générale, l'acculturation tout court n'en est qu'à ses tout débuts ${ }^{14}$. Parallèlement

9. Vera Bácskai, A vállalkozók előfutárai. Nagykereskedók a reformkori Pesten, Budapest, Magvető, 1989 ; Catherine Horel, « Les entrepreneurs juifs et la naissance du capitalisme en Hongrie 1830-1850 », Cahiers d'études hongroises, 1995, p. 186-201.

10. Rózsa Osztern, Zsidó újságírók és szépírók a magyarországi németnyelvú idôszaki sajtóban, a „Pester Lloyd” megalapításáig, 1854-ig, Budapest, Pfeifer Ferdinánd, 1930 ; Aladár Komlós, Magyar-zsidó szellemtörténet a reformkortól a holocaustig, Budapest, Múlt és Jövő, 1997, 2 vol., t. I, p. 55-66.

11. Béla Bernstein, «Reformmozgalmak a magyar zsidóság körében 1848-ban », dans Évkönyv. 1898, dir. Vilmos Bacher et József Bánóczi, Budapest, IMIT, 1898, p. 251-265 ; Michael K. Silber, « The Social Composition of the Pest Radical Reform Society (Genossenschaft für Reform im Judenthum), 1848-1852 », Jewish Social Studies, n 3, 1995, p. 99-128.

12. Michael Silber, « The Historical Experience of German Jewry and Its Impact on Haskalah and Reform in Hungary », dans Toward Modernity. The European Jewish Model, dir. Jacob Katz, New Brunswick/Oxford, Transaction Books, 1987, p. 107-157, ici p. 117, 121-125.

13. Jacob Katz, A House Divided. Orthodoxy and Schism in Nineteenth-Century Central European Jewry. Hanover/Londres, University Press of New England, 1998, p. 31-233. En français, on pourra consulter Catherine Horel, « Orthodoxes et Néologues : le Congrès des Juifs de Hongrie et la scission de la communauté, 1868-1869 », Études Danubiennes, 1994/1, p. 25-42 ; Sur la mouvance «statu quo ante », qui créera finalement, elle aussi, sa propre organisation nationale en 1927, voir Howard Lupovitch, « Between Orthodox Judaism and Neology : The Origins of the Status Quo Movement », Jewish Social Studies, n² 2, 2003, p. 123-153.

14. Les Juifs originaires de Galicie étaient naturellement tous yiddishophones, de même que la grande partie des Juifs immigrés de Bohème et de Moravie où l'abandon du yiddish, par un long processus qui ne s'acheva que vers la fin des années 1860 , ne s'amorca réellement qu'à partir des années 1780, suite à l'ouverture des 
aux premiers signes de la sécularisation de la population juive urbaine ${ }^{15}$, ces décennies sont également marquées par le succès phénoménal de la yeshiva de Pozsony (Pressburg, aujourd'hui Bratislava) dirigée par le rabbin Mosheh Sofer/Schreiber, le « Hatam Sofer » (1763-1839) et qui, à son apogée, accueillit 400 élèves, ainsi que par une efflorescence des yeshivot dirigées par les disciples de cette personnalité phare de l'orthodoxie religieuse juive. Dans ce laps de temps compris entre le déclin de ces institutions en Europe centrale (et notamment la yeshiva de Prague qui, au début des années 1840 , a déjà sombré dans l'obscurité) et l'émergence des yeshivot lithuaniennes, cet épanouissement érigea provisoirement la Hongrie en « centre de gravité du monde des yeshivot ${ }^{16}$.

Du point de vue de l'histoire politique des Juifs de Hongrie, les années 1840 sont marquées par une évolution paradoxale : elles sont à la fois celles de la montée en influence des forces politiques libérales et de l'impopularité croissante de l'émancipation des Juifs ; celles de l'acceptation, par une partie croissante des élites politiques et culturelles, de l'inévitable fin du régime féodal et donc de l'introduction de l'égalité forcément inconditionnelle de tous devant la loi, ainsi que le triomphe, dans le camp réformiste libéral, de l'idée d'une émancipation juive soit partielle, c'est-à-dire offerte aux seules couches acculturées de la population juive, soit conditionnelle, c'est-à-dire offerte en échange d'une réforme radicale préalable de la religion juive, seul vecteur désormais légitime d'une identité juive appelée à être circonscrite à l'espace religieux. Lors de la réunion de la diète de 1839-1840, la chambre basse vota, à une large majorité, un projet de loi mettant les Juifs sur un pied d'égalité avec les populations non nobles du pays. Le projet de loi échoua seulement à la chambre des pairs ${ }^{17}$. Quatre ans plus tard, à la diète de 1843-1844, le texte de loi sur l'émancipation achoppa dès sa présentation à la chambre basse qui la rejeta par 35 voix contre $13^{18}$. À la dernière réunion de la diète féodale, en 1847-1848, aucun projet de loi de la sorte ne fut même présenté devant les chambres qui, un mois après le déclenchement de la révolution, abolirent le régime féodal et accordèrent par les lois d'avril 1848 l'égalité des droits à tous les citoyens du pays - à l'exception des Juifs ${ }^{19}$. En votant finalement leur émancipation le 28 juillet 1849, à quelques semaines d'une inévitable défaite de la guerre de libération menée contre les Habsbourg et leur allié russe, et donc dans un geste de valeur

Normalschulen juives établies sur l'injonction de l'Edit de Tolérance. En Hongrie, le premier sermon tenu dans une langue autre que le yiddish, en l'occurence l'allemand, fut prononcé à Pest en 1827 par le Prediger Josef Bach, mais pour ce qui est des masses de la population juive, le passage à l'allemand, puis au hongrois, ou plus rarement directement au hongrois, ne commença que dans les années 1850. Hillel J. Kieval, Languages of Community : The Jewish Experience in the Czech Lands, Berkeley, University of California Press, 2000, p. 34, 124-125, 142 ; Sándor Büchler, A zsidók története Budapesten a legrégibb idóktól 1867-ig. Bp., IMIT, 1901, p. 402 ; William O. McCagg Jr., A History of Habsburg Jews, 1670-1918. Bloomington/Indianapolis, Indiana University Press, 1989, p. 128 ; M. K. Silber, « Hungary Before 1918 », art. cit., p. 777.

15. Elias Oesterreicher, Der Jude in Ungarn wie er war, wie er ist und wie er seyn wird, Pesth, TrattnerKárolyi, 1842, p. 57 ; Leopold Löw, Zur neueren Geschichte der Juden in Ungarn. Beitrag zur allgemeinen Rechts-, Religions- und Kulturgeschichte, Budapest, Ludwig Aigner, 1874, p. 153 ; S. Büchler, A zsidók története Budapesten, op. cit., p. 400 ; M. Silber, « The Historical Experience », art. cit., p. 133-134; id., « The Social Composition of the Pest Radical Reform Society », art. cit., p. 115-116 ; J. Katz, A House Divided, op. cit., p. 34, 43-44.

16. M. K. Silber, «Hungary Before $1918 »$, art. cit., p. 775 ; id., « Sofer, Mosheh», dans The YIVO Encyclopedia, op. cit., t. II, p. 1776 ; H. J. Kieval, Languages of Community, op. cit., p. 62.

17. Les propositions de la chambre des pairs visant à améliorer la condition des Juifs furent à leur tour partiellement censurées par l'empereur. Même ainsi, la loi finalement entérinée en 1840 représenta une avancée considérable, permettant enfin aux Juifs de s'installer dans les villes royales libres, les villes minières leur demeurant cependant interdites. Zs. Groszmann, A magyar zsidók V. Ferdinánd alatt, op. cit., p. 5-10.

18. Ibid., p. 23-25 ; L. Simon, Zsidókérdés a magyar reformkorban, op. cit., p. 50-59.

19. Ibid., p. 68-74. 
purement symbolique, la Hongrie fut, comme le nota Michael Silber, « le dernier pays d'Europe centrale à accorder l'émancipation au cours des révolutions de $1848-1849{ }^{20}$.

\section{Émancipation et conversion : des discours contradictoires}

Du point de vue de l'histoire des Juifs de Hongrie, le Vormärz hongrois s'est caractérisé ainsi par deux dynamiques interdépendantes : d'une part les débuts de l'acculturation, de la sécularisation et de l'ascension sociale des Juifs, d'autre part la naissance et le laborieux cheminement dans l'esprit de l'élite politique de l'idée que les Juifs devaient être reconnus comme citoyens égaux d'une Hongrie libérale et bourgeoise à créer et pouvaient devenir sous certaines conditions - membres à part entière de la nation hongroise. Ce mouvement conjoint - et la chose est en soi significative des défis qui attendent les Juifs à l'aube de leur intégration dans la société hongroise - alla de pair avec l'apparition dans le débat public de la question de leur conversion. Il serait exagéré de dire que les contemporains y virent un sujet d'actualité brûlant, mais ils se mirent à en parler. La plupart des positions de principe et des jugements sur la nature et la conséquence de la conversion que les divers camps répéteront à l'envi au cours des décennies suivantes trouvèrent à ce moment-là leur première formulation.

Certains, moins nombreux qu'en Allemagne, appelèrent à la conversion des Juifs. Dans l'introduction d'un roman publié en 1836 et dédié à ses « frères bien-aimés », les Juifs « opprimés arbitrairement et haïs sans raison », l'écrivain Mihál Stancsics, un des très rares intellectuels de l'époque à être né dans une famille de serfs, estima que, compte tenu de la force des préjugés, les Juifs, quoiqu'innocents des accusations formulées à leur encontre, avaient tout intérêt à se convertir plutôt que d'attendre une émancipation incertaine ${ }^{21}$. L’ingénieur agronome János Udvardy Cserna, membre de l'Académie des Sciences de Hongrie, était loin de manifester une telle empathie pour les Juifs. Sa position, qu'il défendit dans un article publié quatre ans plus tard, était cependant bien plus représentative de l'opinion de ceux qui voyaient la solution de la « question juive » naissante dans l'abandon par les Juifs de leur religion. Elle était également typique du changement survenu depuis les Lumières dans l'interprétation de la conversion des Juifs, l'accent se déplaçant de la vérité théologique du christianisme vers la supériorité de sa morale. L'ardeur au travail, l'intelligence et le salutaire esprit commercial des Juifs plaidaient en faveur de leur émancipation, estimait l'ingénieur, mais la «morale » de la religion juive, morale fourbe qui leur commandait de n'aimer que leurs coreligionnaires et excluait ainsi la possibilité de leur « amalgamation » avec les citoyens chrétiens, interdisait qu' on la leur accordât, sous peine de voir la Hongrie asservie par les Juifs. S'ils voulaient obtenir l'égalité des droits, les Juifs devaient se convertir, ou réformer leur religion de telle manière que « tout son esprit exhalât la morale de la religion chrétienne », ce qui revenait à peu près au même ${ }^{22}$. On retrouve une variante de cette idée dans le pamphlet d'un certain G. J. paru en 1843. Se concevant comme le peuple élu de Dieu dispersé dans le monde en raison de ses péchés, les Juifs vivaient dans la seule attente du Messie et de leur retour en Terre promise. De ce fait, ils étaient incapables de considérer la terre où ils vivaient comme leur patrie, et ses habitants comme leurs compatriotes, bref de se fondre dans la nation hongroise. Au lieu de leur émancipation, dont le seul résultat, compte tenu du pouvoir économique des

20. M. Silber, « The Historical Experience », art. cit., p. 137.

21. Mihál Stancsics, Pazardi, Kolozsvár, Barra Gábor, 1836, p. 3, 7-8. Né d'un père croate et d'une mère slovaque sous le nom de Mihajlo Stančić, il «magyarisa » son nom en Mihály Táncsics en 1848, après avoir signé ses livres publiés dans les années 1840 sous le nom de Mihál Stancsics.

22. Udvardy, « A’ zsidókról gazdasági tekintetben », Ismertetó, 31 mai 1840, p. 687-695. 
Juifs, serait la transformation de la Hongrie en «pays juif », la seule solution résidait dans l'adoption par les Juifs de la religion catholique ${ }^{23}$.

Face à ces attentes, la position de principe qui, officiellement du moins, demeurera celle du pouvoir politique hongrois jusqu'à la fin de la monarchie dualiste, fut avancée pour la première fois par le baron József Eötvös, écrivain, homme politique réformiste et futur ministre des Cultes et de l'Instruction publique en 1848, puis entre 1867 et 1871. Paru en 1841, son essai - à mi-chemin entre l'étude scientifique et le pamphlet passionné - appela à l'émancipation immédiate et sans condition des Juifs. En tant que catholique fervent, Eötvös était convaincu que la venue du Christ ayant mis un terme à la mission du judaïsme, le cours naturel de l'histoire allait mener les Juifs à embrasser le christianisme. Toutefois, comme leur conversion ne pouvait être valable et souhaitable que si elle était mue par une foi religieuse sincère, toute pression politique était forcément condamnable. En tant qu'homme politique libéral, Eötvös ne pouvait donc concevoir qu'en échange de l'égalité des droits - à laquelle les Juifs, comme tout homme, avaient naturellement droit - on pût exiger d'eux qu'ils renonçassent à leur foi. Leur refus du baptême opportuniste, la fidélité qu'ils vouaient à une religion qui les maintenait en servitude était justement leur trait de caractère le plus noble ${ }^{24}$. Aux côtés d'Eötvös, d'autres intellectuels et hommes politiques le professeur de droit et pasteur luthérien Károly Rumy en 1843, les députés Ödön Beöthy et Szabbás Vukovics à la chambre basse de la diète en 1844 - fustigèrent l'exigence immorale d'une conversion réalisée pour des considérations politiques et s'attachèrent à démontrer la parfaite capacité des adeptes de la religion juive à s'intégrer en tant que tels dans la nation hongroise ${ }^{25}$.

Les Juifs défendirent naturellement une position identique. Dès lors que les Juifs de Hongrie faisaient montre de leur attachement à leur patrie, écrivit en 1840 Löw/Arszlán Schwab, le grand rabbin de la communauté juive de Pest, qu'ils en respectaient les lois et s'efforçaient de « s'associer à leurs concitoyens » dans leur langue et leur culture, un « vrai patriote » ne pouvait songer à réclamer que, pour prix de leur intégration dans la nation, ils renoncent également à la foi de leurs ancêtres ${ }^{26}$. Quant à ceux qui cédaient à la tentation, affirma, en 1844, le jeune Leopold Löw, fervent partisan de la « magyarisation » des Juifs et le rabbin hongrois parmi les plus engagés dans la lutte pour l'émancipation des Juifs, ils étaient sans exception motivés par un intérêt matériel égoïste. L'État ne pouvait donc ambitionner de s'adjoindre des citoyens si peu vertueux ${ }^{27}$.

Pour ce qui était enfin des chances qu'avait un Juif de reléguer par sa conversion ses origines aux oubliettes de la mémoire collective, là aussi, l'opinion qui apparaîtra comme un truisme au tournant du siècle était déjà généralement admise : ces chances étaient nulles. Comme le déclarait un personnage d'une pièce jouée en 1847 : « Certes, mon père m'a baptisé alors que j'étais encore enfant, mais l'eau de baptême n'efface pas le nom de $\mathrm{Juif}^{28}$. » Et de fait, certains tinrent dès cette époque des propos qui illustrent à quel point les

23. G. J., Némelly Igénytelen Nézetek, vallásilag véve, A’magyarhoni zsidók'meghonosítása”s a'magyar nemzetteli egybeolvadása ügyében. Kőszeg, Reichard Károly, 1843.

24. József Eötvös, A zsidók emancipációja [1841], Budapest, Magvető, 1981.

25. [Rumy Károly :] «Elfogulatlan elmélkedés a zsidó társasági viszonyai, emancipatiója, szellemi s tudományos törekvései fölött », Századunk, 26 octobre 1843, p. 685-687, 29 octobre 1843, p. 694-696 ; Ferencz Kovács, Az 1843/44-ik évi magyar országgyúlési alsó tábla kerületi üléseinek naplója, Budapest, FranklinTársulat, 1894, 6 vol., t. 6, p. 11, 17.

26. Arszlán Schwab, A’ zsidók, Buda, A’ Magyar Kir. Egyetem’ betúivel, 1840, p. 54-55.

27. Leopold Löw, « Sendschreiben an Herrn Dr. Jos. Szekács, Prediger der evang. Gemeinde zu Pesth », Allgemeine Zeitung des Judenthums, 25 novembre 1844, p. 681-690.

28. Zsigmond Czakó, Összes múvei, Budapest, Aigner Lajos, s. d. [1883], 2 vol., t. I, p. 326. 
vues essentialistes prédatèrent la diffusion des thèses raciales pseudo-scientifiques. Dans une lettre du 5 janvier 1848 adressée à Pál Nyáry, ancien directeur du Théâtre National, le célèbre acteur - et par ailleurs fervent libéral - Gábor Egressy fit, à propos de l'auteur dramatique Hugó Károly, converti quelques années plus tôt et dont on reparlera plus bas, la remarque suivante :

Je ne me considère pas, cher Monsieur, un homme de préjugés, mais je dois bien arriver à la conclusion [...] que le Juif reste un Juif envers et contre tout. J'en ai acquis la conviction. Jamais et sous aucune forme cette race ne peut se renier. Dans toutes les manifestations de son esprit, on perçoit, on ressent le goût, l'odeur, la couleur de ses particularités raciales ${ }^{29}$.

Comme on le voit, la nouveauté ne résidait pas seulement dans l'apparition de la conversion comme objet de débat, mais également dans la transformation de la signification qui lui était attribuée. Marque d'une rupture fondamentale avec les siècles précédents, la conversion était désormais une question avant tout séculière et non plus religieuse, politique et non plus théologique. Le christianisme était principalement affaire de morale et de culture, et la conversion, un acte permettant non tant de sauver son âme, que d'intégrer la nation (chrétienne) hongroise.

Mais qu'en était-il des convertis ?

\section{Les Juifs convertis : chiffres et profil social}

Le soudain intérêt porté à la conversion des Juifs fut certainement alimenté par le baptême de quelques-uns des hommes d'affaires juifs les plus connus de l'époque. Le côté spectaculaire de ces cas individuels amena les contemporains à y voir un phénomène général. Dans un livre sur son séjour en Hongrie publié en 1840, l'écrivaine anglaise Julia Pardoe affirmait que «nombre » des familles les plus fortunées de la communauté juive s'étaient converties au christianisme et avaient acheté leur titre de noblesse afin de jouir ainsi « de toutes les immunités des classes privilégiées $»^{30}$. En réalité, il y avait à cette date trois familles seulement qui, une fois converties, avaient reçu un titre de noblesse hongrois : les Lackenbacher en 1824, les Ullmann un an plus tard et les Adelsberg en $1837^{31}$. Dans son ouvrage apologétique sur l'histoire des Juifs hongrois publié en 1922, le rabbin et historien Lajos Venetianer parla du «caractère endémique » des conversions dans les « milieux cultivés » de l'époque, puis il cita en tout une personne et quatre familles ${ }^{32}$.

Ceci n'est pas pour dire que les conversions ne devinrent pas plus fréquentes qu'auparavant, elles le furent sans nul doute, même s'il est également certain qu'on n'assista pas en Hongrie à des vagues de conversions telles que celles touchant les Juifs de Berlin entre 1770 et $1830^{33}$. Il s'agit plutôt de ce que, du fait du point de départ, c'est-à-dire du nombre rarissime de conversions jusqu'aux premières décennies du XIX ${ }^{\mathrm{e}}$ siècle, l'augmentation des apostasies pouvait être à la fois spectaculaire et finalement limitée en nombre.

29. Mária R. Hoffmann, « Egressy Gábor levele Hugó Károlyról », Irodalomtörténeti Közlemények, 1931/3, p. 333-335, ici p. 335 .

30. Miss Pardoe, The City of the Magyar, or Hungary and her Institutions in 1839-40, Londres, George Virtue, 1840, 3 vol., t. 3, p. 301.

31. János Illésy et Béla Pettkó, A királyi könyvek, Budapest, 1895, p. 14, 124, 226.

32. L. Venetianer, A magyar zsidóság története, op. cit., p. 157.

33. Steven M. Lowenstein, The Berlin Jewish Community. Enlightenment, Family and Crisis, 1770-1830, New York/Oxford, Oxford University Press, 1994, p. 120-133. 
Nous ignorons le nombre exact de ces conversions. La seule manière de l'établir nécessiterait de compulser un par un les registres de baptême de toutes les paroisses de Hongrie. Une telle recherche, même limitée aux paroisses des trois villes de la future Budapest, prendrait à elle seule des années. Le travail d'Árpád Welker sur les registres de baptême des paroisses protestantes de Pest et nos propres recherches portant sur celles de la paroisse catholique du Lipótváros, quartier central de Pest et fief naissant de la grande bourgeoisie juive, permettent cependant de tracer la dynamique des conversions à l'ère des réformes. Jusqu'au début des années 1840, on peut seulement parler de quelques cas exceptionnels. Leur nombre connut ensuite une légère mais nette progression, pour finalement exploser en 1848, année de la première des quatre vagues de conversions dans l'histoire moderne des Juifs hongrois ${ }^{34}$. À la paroisse catholique du Lipótváros, on baptisa 23 Juifs entre 1840 et 1847 , puis 26 dans la seule période de mars à août $1848^{35}$. Les paroisses luthériennes et calvinistes de Pest baptisèrent une soixantaine de personnes en $1848^{36}$. En extrapolant à partir de ces chiffres, on peut estimer qu'environ 200 Juifs se convertirent à « Budapest » au cours de cette année, soit 1,09\% des 18265 Juifs vivant à Pest, Buda et Óbuda ${ }^{37}$.

Qui étaient ces convertis ? L'étude de Welker ne fournit aucune indication à ce sujet. Pour ce qui est des 52 personnes baptisées à la paroisse catholique du Lipótváros entre 1840 et 1849 , leur grande majorité, 36 personnes $(69,2 \%)$, étaient des hommes. L'âge des convertis est indiqué - ou lisible - dans 44 cas : 29 étaient des adultes, 15 des enfants de moins de 18 ans. L'âge moyen des adultes était de 29,2 ans, celui des enfants de 5 ans. La particularité de l'année 1848 fut la conversion de familles entières. Les années précédentes, il n'y en eut aucune, cette année-là, 16 des 26 baptisés appartenaient à trois familles, deux couples avec trois enfants, un couple et leurs quatre enfants.

Au-delà de ces quelques informations, nous sommes dans l'impossibilité d'établir une typologie statistique acceptable des catégories sociales les plus concernées. Outre le nombre réduit de cette base de donnée, l'irrégularité, voire dans quelques cas l'illisibilité de l'indication de la profession des Juifs baptisés - 9 cas indiqués ou lisibles sur les 36 personnes adultes - rend toute conclusion hasardeuse. À titre d'indication : il y avait parmi les convertis 2 grossistes, 2 médecins, un commerçant, un apprenti de commerce, une vendeuse en confection et une servante. Les registres indiquèrent un peu plus souvent, dans 31 cas en tout, la profession du père des baptisés : 14 convertis avaient pour père des commerçants, 10 des grossistes, 4 frères et sœurs un dentiste, 2 baptisés des médecins, enfin, une jeune femme de 23 ans avait pour père un cocher de fiacre. On notera que si les grossistes étaient sans nul doute des hommes d'un certain niveau de fortune, les « commerçants » pouvaient aussi bien être des gens aisés que des personnes de condition modeste. On s'en tiendra donc à la conclusion qu'une différence semble se dessiner entre

34. La seconde vague eut lieu après l'accusation de meurtre rituel de Tiszaeszlár de 1882, la troisième fut provoquée par la crise antisémite accompagnant et suivant les révolutions de 1918-1919, la dernière survint à partir de 1938, l'année du vote de la «première loi juive ». Entre 1896 et 1942, période pour laquelle nous disposons de statistiques nationales sur les conversions juives, 56858 personnes juives furent baptisées en Hongrie, dont 9071 en 1918-1919, et 14654 en 1938-1939. Pour un tableau récapitulatif, voir Gyula Zeke, « Statisztikai mellékletek », dans Hét évtized a hazai zsidóság életében, dir. L. Ferenc Lendvai et al., Budapest, MTA Filozófiai Intézet, 1990, 2 vol., t. I, p. 185-199, ici p. 194-195.

35. Magyar Nemzeti Levéltár [désormais MNL], Szentistvánvárosi (Lipótvárosi) r. kath. plébánia, kereszteltek anyakönyve, A61.

36. Árpád Welker, «Zsidó betérések a protestáns felekezetekbe Pesten, 1895 előtt », Korall, 2007/27, p. 94109, ici p. 99.

37. József Kőrösi, « Buda és Ó-buda városa népességének évenkénti kimutatása 1813-tól 1857-ig », Statisztikai Havi Füzetek, n 5, 1881, p. 131-137, ici p. 136. 
ces quelques cas, et les Juifs baptisés au Consistoire lithuanien de l'Église orthodoxe russe, ceux convertis à Varsovie, ou plus près de la Hongrie, les Juifs baptisés à Vienne. La majorité de ces derniers étaient des personnes d'origine et de situation humble, souvent en marge de la société juive, ce qui, d'évidence, n'était pas le cas des Juifs baptisés à la paroisse catholique du Lipótváros dans les années $1840^{38}$.

\section{Les motivations des convertis}

Mais qu'est-ce que cela nous dit vraiment des convertis eux-mêmes ? À défaut de confessions personnelles des personnes concernées ou de témoignages de contemporains sur leurs conversions, les données statistiques sur le sexe, l'âge, la profession des convertis ou de leurs parents nous semblent être d'une portée limitée. En effet, eu égard à la question essentielle des motivations, ces données autorisent tout au plus une spéculation raisonnée quant au motif premier d'un acte dont les causes étaient généralement plurielles et indissolublement enchevêtrées. Les objectifs immédiats - le désir d'obtenir un emploi, la recherche d'un avantage matériel ou social, le mariage avec une personne chrétienne - s'accompagnaient de motivations profondes plus complexes, parfois avouées, souvent plus ou moins inconscientes. Enfin, et surtout, pourrait-on dire : ces données n'offrent naturellement aucune réponse quant à la question du comment, du cheminement personnel menant à la conversion.

Des confessions personnelles de convertis ou des témoignages de leurs contemporains, nous n'en disposons, sans surprise, que dans les cas d'intellectuels et d'hommes d'affaires qui écrivirent sur eux-mêmes ou sur quelque sujet que ce fût, et/ou éveillèrent la curiosité de leurs contemporains. Comme ailleurs en Europe centrale, la montée en fréquence parmi les convertis, de telles personnes, c'est-à-dire des membres de l'élite de la société juive, constitua la marque fondamentale des conversions à l'ère moderne ${ }^{39}$. Ce fut aussi la source d'une inquiétude de plus en plus aiguë pour les rabbins et les Juifs " engagés », perplexes, furieux ou effrayés devant l'abandon de la foi de leurs ancêtres par ceux-là même qui, en tant que membres les plus illustres de leur communauté, servaient inévitablement de référence sinon de modèle à leurs coreligionnaires.

Pour la Hongrie du Vormärz, nous avons pu réunir une vingtaine de portraits de convertis, à partir desquels nous avons tenté d'établir une typologie non pas selon leur statut social, mais selon leurs motivations, ou plutôt la cause immédiate la plus probable de leur conversion. Le résultat est sans surprise : comme ailleurs en Europe centrale au cours de cette période, quelques-uns se convertirent par foi religieuse, d'autres, plus nombreux, afin de pouvoir donner toute mesure à leurs ambitions entrepreneuriales, et/ou intégrer socialement l'élite chrétienne ; certains se firent baptiser pour se débarrasser d'un obstacle limitant leur participation aux affaires publiques, d'autres pour obtenir un emploi. Seule femme parmi cette vingtaine de personnes, la jeune orpheline Ernesztin Mauthner s'est convertie à l'insu de ses tuteurs à l'âge de 16 ans pour épouser le procureur de la ville de

38. Michael Stanislawski, « Jewish Apostasy in Russia : A Tentative Typology », dans Jewish Apostasy in the Modern World, dir. Todd M. Endelman, New York/Londres, Holmes \& Meier, 1987, p. 189-205; Todd M. Endelman, « Jewish Converts in Nineteenth-Century Warsaw. À Quantitative Analysis », Jewish Social Studies, $\mathrm{n}^{\circ}$ 1, 1997, p. 28-59 ; Anna L. Staudacher, Jüdische Konvertiten in Wien 1782-1868, Francfort-sur-le-Main, Peter Lang, 2002, 2 vol. Michael Stanislawski a utilisé une base de 244 conversions enregistrées et rassemblées par le Consistoire lithuanien de l'Église orthodoxe russe de 1819 à 1911. Todd Endelman a étudié une liste établie au début du XX $\mathrm{XX}^{\mathrm{e}}$ siècle de 1796 Juifs convertis à Varsovie entre 1800 et 1903. Anna Staudacher a compulsé les registres de baptême catholiques et protestants de Vienne et recensa 3000 conversions pour la période 1782-1868.

39. Jacob Katz, Out of the Ghetto. The Social Background of Jewish Emancipation, 1770-1870, Cambridge, Mass., Harvard University Press, 1973, p. 122. 
Buda, de toute évidence par amour. Amour déçu d'ailleurs, puisqu'il s'avéra rapidement que son mari, Károly Farkas, convoitait avant tout les 300000 forints qui devaient revenir à sa femme en héritage ${ }^{40}$. En 1848, enfin, l'année de tous les enthousiasmes et de toutes les déceptions, certains abandonnèrent la religion et la communauté juive par désespoir d'une révolution qui, au lieu de leur amener l'émancipation, déclencha au printemps 1848 un mouvement de manifestions et d'émeutes anti-juives sans précédent dans le pays ${ }^{41}$.

Si l'on se penche cependant plus attentivement sur ces cas, et en particulier sur ceux où les sources nous permettent une analyse un peu plus précise, les motivations apparaissent plus compliquées, la cause première de la conversion plus difficile à établir. Parmi cette vingtaine de personnes, l'histoire de quatre d'entre elles nous semble particulièrement caractéristique des conversions touchant cette couche naissante d'entrepreneurs et d'intellectuels juifs, de la diversité de leurs motivations, mais aussi - et je conclurai sur cet aspect-là - de la spécificité conjoncturelle d'une grande partie de ces motivations.

\section{Quatre études de cas}

Moritz Ullmann (1783-1847).

Par la date de sa conversion, le commerçant et entrepreneur Moritz Ullmann ${ }^{42}$, le frère aîné de Gabriel Ullmann, est le premier de nos quatre convertis. Il fut baptisé dans la foi catholique à Vienne le $1^{\mathrm{er}}$ mars 1825, à l'âge de 42 ans. De Moritz Mosheh, il devint Moritz Johann. Ses parents étaient alors déjà décédés ${ }^{43}$. Sa femme, Frommet/Szidonia Hirschl, dont il divorça en 1832, et ses filles restèrent juives, ses six fils furent baptisés à Budapest huit mois plus tard ${ }^{44}$.

Le père de Moritz Ullmann, Abraham, était originaire de la ville bavaroise de Fürth, il immigra en Hongrie dans le dernier tiers du XVIII ${ }^{\text {ème }}$ siècle en compagnie de ses trois frères. À sa mort à Pest en 1823, il était un commerçant aisé. Son fils Moritz fit fortune dans le commerce de laine, de blé, de cuir et de tabac. Lors de sa conversion, il était un des hommes d'affaires les plus riches du pays. De ce fait, il était aussi un des Juifs les plus connus, membre depuis 1806 de la direction de la communauté juive de Pest ${ }^{45}$, qui, grâce au poids économique de ses membres, n'allait pas tarder à ravir à Pozsony le statut de communauté la plus influente du pays. À l'instar de ses pairs, il n'a pas été élu à cette direction par les membres de la communauté, comme cela se fera après la reconnaissance par les autorités des statuts de la communauté juive de Pest en 1833, mais a été nommé d'office par la municipalité parmi les riches commerçants de la ville ${ }^{46}$. Il se retrouva alors dans une direction dont plusieurs membres avaient tout fait pour empêcher que son père et

40. V. Bácskai, A vállalkozók elófutárai, op. cit., p. 195-196.

41. György Haraszti, «Az 1848. évi magyarországi zsidóösszeírás háttere és mozgatórugói » dans id., Két világ határán, Budapest, Múlt és Jövő, 1999, p. 185-219, ici p. 190-194 ; Julia Richers, Jüdisches Budapest. Kulturelle Topographien einer Stadtgemeinde im 19. Jahrhundert, Köln, Böhlau Verlag, 2009, p. 277-280.

42. Sur Moritz Ullmann et sa famille voir Béla Kempelen, Magyar zsidó családok [19371939], Budapest, Makkabi, 1999, 3 vol., t. 1, p. 96-104; V. Bácskai, A vállalkozók előfutárai, op. cit., p. 141-153; Michael Silber, «Ullmann Family», dans The YIVO Encyclopedia, op. cit. (http://www.yivoencyclopedia.org/article.aspx/Ullmann_Family)

43. A. L. Staudacher, Jüdische Konvertiten, op. cit., t. 2, p. 506.

44. MNL, Szentistvánvárosi (Lipótvárosi) r. kath. plébánia, kereszteltek anyakönyve, A60.

45. Zs. Groszmann, « Az Ullmann-botrány », Egyenlöség, 7 septembre 1935, p. 12.

46. Zs. Groszmann, «A pesti zsidó gyülekezet alkotmányának története », dans Emlékkönyv Dr. Hevesi Simon pesti vezetó fórabbinak, papi múködése negyvenedik évfordulójára dir. Guttmann Mihály et al., Budapest, Neuwald Illés, 1934, p. 126-172, ici p. 127-128. 
lui-même, potentiels concurrents commerciaux, reçoivent le droit de résidence à Pest ${ }^{47}$. En 1813 , ses collègues l'élirent "erste Vorsteher ${ }^{48}$, c'est-à-dire dirigeant de fait des Juifs de Pest, non parce qu'ils l'appréciaient, mais parce qu'il était sans conteste le plus fortuné et le plus puissant d'entre eux. En fait, le moins qu'on puisse dire est qu'ils ne l'appréciaient pas. Des querelles incessantes déchirèrent la communauté juive, les plaintes déposées contre Moritz Ullmann par ses coreligionnaires auprès de la municipalité se multipliaient. Ces plaintes visaient sa direction autoritaire, ses décisions arbitraires et on le disait coléreux et violent ${ }^{49}$.

Pour ce qui est de son identité juive, l'auteur d'une plainte écrit dans une lettre datant probablement de 1817 : «Il appartient à notre religion seulement en ce qu'il porte sans aucune raison le nom de Juif ${ }^{50}$. » On ignore la part de vrai dans cette affirmation, mais on sait qu'en 1822, Ullmann a engagé comme comptable et peut-être même comme précepteur de ses enfants un certain Károly Kohlmann qui, après avoir été le premier instituteur de l'école élémentaire de la communauté juive de Pest fondée en 1814, s'est converti au catholicisme en $1816^{51}$. Qu'Ullmann ait pris un Juif converti à son service permet à tout le moins de supposer qu'il était alors déjà largement éloigné de la foi juive et des critères de valeurs de la société juive traditionnelle. Il démissionna de la tête de la communauté juive en 1823 , deux ans avant sa conversion ${ }^{52}$.

Dans leurs articles publiés dans l'entre-deux-guerres, Bernát Mandl et Zsigmond Groszmann étaient convaincus que les querelles au sein de la communauté et son impopularité croissante furent la cause principale de sa conversion ${ }^{53}$. C'est possible. L'historienne hongroise Vera Bácskai et l'américain William McCagg ont avancé une raison qui nous semble plus convaincante : en embrassant le catholicisme, Ullmann ouvrit la voie à son anoblissement, obtenu neuf mois plus tard, en décembre 1825 , ce qui dans le régime féodal lui offrit non seulement l'exemption des impôts, et l'accès illimité à la propriété, mais aussi la possibilité, en tant qu'entrepreneur, de donner toute la mesure de son ambition ${ }^{54}$. Il semble toutefois que sa conversion avait un motif supplémentaire : le souhait pour lui-même et encore plus pour ses fils d'intégrer l'élite traditionnelle. Certes, il resta dans les affaires jusqu'à sa mort, son plus grand fait d'arme ayant été la fondation en 1840 de la première banque commerciale hongroise dont il fut le premier président. Mais, en 1832, quelques mois après avoir divorcé de sa première épouse ${ }^{55}$, il se remaria avec une femme issue de la noblesse hongroise et tenta - en vain - d'être élu au Casino National, le club des magnats

47. V. Bácskai, A vállalkozók elöfutárai, op. cit., p. 140.

48. Zs. Groszmann, « A pesti zsidó gyülekezet », art. cit., p. 129.

49. Bernát Mandl, « Két tragikus zsidó asszony », Egyenlóség, 9 avril 1921. p. 11 ; Zs. Groszmann, « Az Ullmann-botrány », art. cit., p. 12 ; Zs. Groszmann, « A pesti zsidóság vezetői », dans Emlékkönyv dr. Kiss Arnold budai vezetö förabbi hetvenedik születésnapjára, dir. Guttmann Mihály et al., Budapest, Lőwinger, 1939 , p. $51-57$, ici, p. 52.

50. Zs. Groszmann, « Az Ullmann-botrány », art. cit., p. 12.

51. Zs. Groszmann, « A pesti zsidó gyülekezet », art. cit., p. 137 ; B. Kempelen Béla, Magyar zsidó családok, op. cit., t. 2, p. 37.

52. Zs. Groszmann, « A pesti zsidóság vezetői », art. cit., p. 52.

53. B. Mandl, « Két tragikus zsidó asszony », art. cit., p. 11 ; Zs. Groszmann, « A pesti zsidóság vezetői », art. cit., p. 52.

54. V. Bácskai, A vállalkozók elófutárai, op. cit., p. 140 ; William O. McCagg, Jr., Jewish Nobles and Geniuses in Modern Hungary, Boulder, East European Quarterly, 1972, p. 60.

55. Selon la légende urbaine pestoise - «c'est ce que m'ont raconté de vieux Pestois dans les années quatre-vingt du siècle dernier », écrivit Mandl -, il se rendit néanmoins chaque vendredi chez son ex-femme et la regardait allumer les bougies de shabbat. B. Mandl, « Két tragikus zsidó asszony », art. cit., p. 11. 
fondé par István Széchenyi ${ }^{56}$. Plus significatif encore : dans son testament, il interdit à ses fils de poursuivre une quelconque activité commerciale, et leur commanda d'acquérir une propriété terrienne noble dont les revenus, joints aux rentes provenant d'une fondation de 150000 forints, devaient être distribués parmi les jeunes nobles désargentés ${ }^{57}$. L'entrée dans l'élite nobiliaire fut certainement l'ambition de ses fils, une ambition d'ailleurs largement satisfaite.

\section{Károly Hugó (1808-1877)}

Notre second converti fut une figure excentrique et haute en couleur, auteur de pièces de théâtre à succès dans la Pest de la seconde moitié des années 1840 et qui sombra ensuite progressivement dans une folie mégalomane pour mourir en 1877, pauvre et oublié de tous. Né à Pest en 1808 sous le nom de Philipp Bernstein, il se convertit vers 1841, à Vienne lui aussi, mais à la religion luthérienne ${ }^{58}$.

Son père, Salamon, était un pauvre commerçant de marchandises d'occasion, d'une culture encore exclusivement juive. Malgré son opposition, sa femme Esther inscrivit leur unique fils dans une école élémentaire luthérienne. Le jeune Philipp alla ensuite au lycée des piaristes où la langue d'enseignement était l'allemand, puis il passa un an à Szeged pour y apprendre le hongrois - qu'il ne réussit jamais à parler correctement. Il entreprit des études de médecine, obtint son diplôme à Varsovie, pratiqua son métier à Pest, partit à Paris où, sous l'influence de Samuel Hahnemann, il devint adepte de l'homéopathie, puis il s'installa en 1841 à Vienne, rêvant de gloire littéraire mais vivant de la médecine ${ }^{59}$. C'est à ce moment-là qu'il abandonna la religion juive afin de pouvoir, selon des membres de sa famille, devenir médecin particulier de familles de haut rang ${ }^{60}$, apparemment donc par opportunisme. Une pièce de théâtre, Das Schauspiel der Welt, qu'il écrivit un an après sa conversion et publia à compte d'auteur en 1844, offre toutefois un autre éclairage. Jeté en prison pour avoir courageusement défendu ses coreligionnaires, le héros juif de la pièce située au Moyen Âge y apprend qu'en réalité il est de naissance chrétienne. Il déclare alors : «Ce que j' ai été, je le reste. Car chevalier ou Juif, à mes yeux, cela ne fait pas de différence », pour ensuite s'écrier : « J'exulte à l'idée que même sur la base instable des préjugés indignes, ces grands enfants - entendons les chrétiens - ne pourront me considérer en quoi que ce soit inférieur à eux ${ }^{61}$ ! » L'aveu laisse penser qu'à l'instar de son héros, Károly Hugó a vécu sa judaïté avant tout comme un stigmate douloureux et son abandon comme une délivrance. Cependant, dans un livre intitulé Das befreite Paradies qu'il publia en 1845, et ce fut l'unique occasion où il s'exprima sur sa conversion, Hugó affirmait : « Je suis en fait un Juif, et en tant que tel, j'étais un homme bon, comme tous les autres de ma tribu. C'est après une longue route que j'ai embrassé la foi luthérienne ${ }^{62}$. » Était-ce là une confession de foi sincère, ou le signe d'un désir d'autojustification? On n'en sait pas plus.

56. Gróf Széchenyi István, Naplói, éd. Gyula Viszota, Budapest, Magyar Történelmi Társulat, 1934, t. 4, p. 241.

57. V. Bácskai, A vállalkozók elófutárai, op. cit., p. 150-151.

58. La source la plus fiable et la plus détaillée sur les jeunes années de Hugó est un article paru en 1894 dont l'auteur a pu compléter ses sources écrites par des témoignages oraux de plusieurs amis et membres de la famille de Hugó. Voir Endre Kőrös, « Hugó Károly ifjúsága », Irodalomtörténeti Közlemények, n³, 1894, p. 320-335.

59. Ibid., p. 320-330 ; György Ádám, Hugó Károly élete és múvei. Kolozsvár, Szent Bonaventura, 1906 ; László Erdélyi Ifj, Hugó Károly élete és müvei, Szeged, Magyar Irodalomtörténeti Intézet, 1933.

60. E. Kőrös, « Hugó Károly ifjúsága », art. cit., p. 330.

61. Ibid., p. 331.

62. Ibid., p. 330. 


\section{Moritz Bloch (1815-1891)}

La conversion, deux ans après Hugó, de Moritz Bloch constitua un véritable choc pour les Juifs de Hongrie. Né en 1815 dans un hameau du nord-est du pays, Bloch grandit dans la misère. Ce fut son père, métayer ruiné devenu «melamed », c'est-à-dire enseignant dans les écoles primaires juives traditionnelles, qui lui inculqua les bases de la religion juive, il étudia ensuite dans plusieurs yeshivot. Le futur théologien protestant et linguiste hongrois avait moins de vingt ans lorsqu'un curé villageois éveilla sa curiosité pour la culture non juive. Il apprit l'allemand, le latin et le grec, acheva ses études secondaires dans une école calviniste de province, puis monta à Pest en 1837. Là, il suivit des cours de mathématiques à l'Institutum Geometricum, l'ancêtre de l'école Polytechnique, tout en apprenant le hongrois et en publiant ses premiers articles, dans la presse allemande, puis bientôt hongroise. Sa religion lui interdisant l'obtention du diplôme, il partit achever ses études à Paris ${ }^{63}$. Il y résidait lorsqu'en 1840, à l'instigation de l'homme politique libéral József Eötvös, il composa un pamphlet en faveur de l'émancipation des Juifs qu'il acheva le 27 février, c'est-à-dire avant que la diète n'ait commencé à débattre du projet de loi sur l'émancipation des Juifs ${ }^{64}$.

Le pamphlet, intitulé Des Juifs, fit de Bloch un des champions les plus connus de la cause de l'émancipation des Juifs en Hongrie. Son argument central fut celui avancé en premier par John Toland, puis rendu classique par Wilhelm Dohm : la liberté étant l'état naturel de l'homme, la corruption morale des Juifs était due à leur seule oppression. Dans son pamphlet, Bloch s'affirmait inévitablement et naturellement hongrois : « Un Juif cultivé qui, né et éduqué en Hongrie, parle la langue de sa patrie, pourrait-il se considérer autrement que Hongrois $^{65}$ ? » Mais il parlait aussi en tant que Juif : il stigmatisa les convertis qui trahissaient les leurs pour des raisons le plus souvent vulgairement matérielles, et fustigea la société chrétienne qui récompensait ces convertis immoraux au lieu de prendre en estime les Juifs demeurant fidèles à leur foi au prix de tous les sacrifices ${ }^{66}$.

Rentré en Hongrie, Bloch traduisit le pamphlet que nous avons déjà cité du grand rabbin de la communauté juive de $\mathrm{Pest}^{67}$, puis il fit paraître une traduction hongroise du Pentateuque assortie de ses propres commentaires. Le second volume, paru fin 1840, indiquait que son auteur était membre de l'Académie des Sciences de Hongrie ${ }^{68}$. Le premier académicien Juif de Hongrie, élu le 5 septembre 1840, collabora ensuite à la publication du premier livre de prière en hongrois ${ }^{69}$, puis, toujours en 1841 , donna une traduction hongroise du livre de Josué ${ }^{70}$.

Le 4 juillet 1843, Bloch s'inscrivit à la faculté de théologie de l'université de Tübingen $^{71}$, cinq semaines après s'être converti à la religion protestante, le 28 mai, dans le

63. Aladár Ballagi, « Ballagi Mór » dans Protestáns Új Képes Naptár 1879. évre, dir. Sándor Dúzs, Budapest, Franklin-Társulat, 1879, p. 17-25, p. 17-19.

64. Móritz Bloch, A’zsidókról, Pesten, Trattner-Károlyi Betűivel, 1840, p. 55.

65. Ibid., p. 47.

66. Ibid., p. 52.

67. A. Schwab, A' zsidók, op. cit.

68. Móricz Bloch, Mózes öt könyve, Buda, A’Magyar Kir. Egyetem’betúivel, 1840-1841, 5 vol. Les deux premiers tomes - Genèse, Exode - parurent en 1840, les trois autres - Lévitique, Nombres et Deutéronome - en 1841.

69. Móricz Rosenthal, Jiszrael könyörgései egész évre, Pozsony, Korn Fülöp, 1841, 2 vol.

70. Bloch Móritz, Elsố jósok, Buda, A’Magyar Kir. Egyetem’betűivel, 1841.

71. László Szögi, Magyarországi diákok németországi egyetemeken és fóiskolákon 1789-1919, Budapest, Eötvös Loránd Tudományegyetem Levéltára, 2001, p. 479. 
village voisin de Notzingen ${ }^{72}$. La nouvelle de sa conversion causa un émoi d'autant plus vif parmi les Juifs hongrois, qu'après sa conversion, dans une lettre aujourd'hui perdue qu'il envoya à la communauté juive de Pest, Bloch appela ses anciens coreligionnaires à suivre son exemple, « sur un ton irrité », comme le rapporta le rabbin Leopold Löw ${ }^{73}$.

Dans l'article qu'il publia à ce sujet dans l'Allgemeine Zeitung des Judenthums, Löw considéra comme une évidence que Bloch avait abandonné la foi de ses pères non par conviction religieuse, mais, pour accéder à une situation à laquelle il ne pouvait prétendre en restant juif. Löw affirmait le tenir de source sûre : deux ans avant sa conversion, Bloch considérait encore qu'abandonner la religion juive ne pouvait être qu'un acte de « vile lâcheté ». Sauf qu'il ne put finalement supporter, selon Löw, d'en être réduit, tout académicien qu'il était, à espérer au mieux un emploi d'enseignant dans quelque communauté juive. Par contre, aussitôt converti, il fut nommé professeur dans un établissement d'enseignement supérieur luthérien ${ }^{74}$.

La seconde interprétation de la conversion de Bloch fut proposée par son fils, Aladár Ballagi, dans le portrait de son père qu'il publia en 1879. Afin de promouvoir la magyarisation des rabbins, écrivait-il, son père lança en 1841 un mouvement pour l'établissement d'un Séminaire rabbinique. Il publia des articles à ce sujet, et lança une collecte de fonds, à laquelle l'homme politique réformateur le plus célèbre de son temps, István Széchenyi, donna à lui seul 200 forints alors que la « richissime » communauté juive de Pest, « au lieu des milliers [de forints] qu'il était en droit d'attendre », se contenta d'une obole de 140 forints. C'est à ce moment-là que profondément choqué et déçu, Bloch aurait pris la décision de quitter une communauté emmurée dans son isolation égoïste, ni capable et désireuse de se rapprocher de la société hongroise ${ }^{75}$.

L'explication d'Aladár Ballagi péchait par deux erreurs. D'une part, Bloch fit campagne pour l'ouverture non d'un séminaire, mais d'un institut de formation d'enseignants juifs ${ }^{76}$. D'autre part, le don de 140 forints de la communauté de Pest, que celle-ci se proposa de verser chaque année, était en fait de loin la somme la plus importante, Széchenyi ne déboursa en réalité que 50 forints ${ }^{77}$. Cela dit, il est certain que l'objectif de Bloch était d'œuvrer à la magyarisation des Juifs. Dans l'article qu'il publia en février 1841 en faveur de la création d'un institut de formation pour enseignants juifs, il exprima son espoir que les Juifs de Hongrie « commençaient enfin à comprendre » que s'ils voulaient obtenir un jour l'émancipation, ils devaient élever leurs enfants dans un esprit hongrois ${ }^{78}$. $\mathrm{Si}$ on considère la réticence évidente des communautés juives de l'époque à ouvrir des écoles élémentaires modernes et inclure dans leur cursus l'apprentissage du hongrois ${ }^{79}$, il est possible que Bloch ait effectivement été déçu par ses coreligionnaires, et que cette déception l'ait définitivement aliéné de sa communauté.

72. A. Ballagi, « Ballagi Mór », art. cit., p. 20.

73. L. Löw, « Sendschreiben an Herrn Dr. Jos. Szekács », art. cit., p. 682.

74. Ibid., p. 682-683, 688 .

75. A. Ballagi, « Ballagi Mór », art. cit., p. 20.

76. Móricz Bloch, « Felszólítás egy magyar-zsidó tanítókat képző intézet ügyében », Pesti Hírlap, 6 février 1841, p. 86-87.

77. Móricz Bloch, « A’Pesten állítandó magyar-zsidó tanítókat képző intézet ügyében », Világ, 23 juin 1841, p. 199.

78. M. Bloch, « Felszólítás », art. cit., p. 87.

79. En 1846, après plusieurs années d'intense propagande en faveurs d'écoles élémentaires pourvues d'un cursus moderne, Leopold Löw ne recensait toujours que 29 communautés juives disposant de tels établissements. M. Silber, « The Historical Experience », art. cit., p. 132. 
Enfin, il est naturellement impossible d'exclure que la conversion de Bloch ait été un acte spirituel sincère, ou reflétant du moins une réelle attirance pour le protestantisme libéral. Il devint en effet théologien, professeur de l'académie de théologie calviniste de Budapest.

\section{Jonás Kunewalder (1803-1888)}

Comme Moritz Ullmann, le dernier de nos quatre convertis était également un homme d'affaires. Il dirigea lui aussi la communauté juive de Pest, sauf qu'il fut un dirigeant bien plus populaire et actif qu'Ullmann. Né à Óbuda en 1804, et enrichi dans le commerce de grains, Jonás Kunewalder devint dans les années 1840 un des commerçants juifs pestois les plus en vue, et certainement le Juif le plus intégré dans les divers clubs et associations réformistes qui œuvraient à la transformation libérale du pays mais qui n'acceptaient les Juifs qu'au compte-gouttes. Kunewalder était l'un d'eux ${ }^{80}$.

Le 26 décembre 1845, Kunewalder fut élu coprésident de la communauté juive de Pest $^{81}$, il s'imposa comme le leader officieux et le porte-parole officiel des Juifs de Hongrie. Le 23 septembre 1847, c'est lui qui, au nom de l'organisation nationale juive mise en place en 1839 pour lutter en faveur de l'émancipation, signa le document demandant l'égalité des droits pour les Juifs de Hongrie, document qui fut envoyé sous forme de lettre circulaire aux comitats du pays et à plusieurs intellectuels de renom ${ }^{82}$. Cet écrit, composé sans aucun doute par Kunewalder en personne, était un écrit amer. Les Juifs ont beau aimer leur patrie, disait-il en substance, celle-ci les considère toujours comme des étrangers. « De devenir Hongrois, ce fut là notre ambition et notre fierté, mais on nous rappelle sans cesse que nous ne sommes toujours pas en droit de nous considérer comme tels ${ }^{83}$. » Mais c'était également là un écrit très étrange : alors qu'en théorie, le document, et, à travers lui, Kunewalder lui-même, parlait naturellement au nom et dans l'intérêt de tous les Juifs du pays, en réalité, Kunewalder se dissociait de l'énorme majorité d'entre eux. En effet, le texte contenait des appels implicites mais parfaitement limpides à une émancipation partielle qui mettrait fin à la stigmatisation de ceux parmi les Juifs dont le patriotisme, l'acculturation et la moralité étaient incontestables ${ }^{84}$ - c'est-à-dire, naturellement, de gens comme Kunewalder.

Puis vint la révolution. Le quatrième des douze points proclamés par les révolutionnaires pestois le 15 mars demandait l'égalité civique et religieuse de tous devant la loi. Le 16 mars, Kunewalder était élu membre du Comité Révolutionnaire fondé à Pest la veille au soir $^{85}$. Le 17 mars, en sa qualité officielle de président de l'organe de représentation des Juifs hongrois, il signa une lettre ouverte adressée à tous les citoyens du pays ${ }^{86}$. Autant la pétition de septembre 1847 était amère, autant cette lettre débordait d'enthousiasme. Kunewalder y affirmait sa certitude absolue que l'émancipation des Juifs était désormais chose

80. Sándor Takáts, Hangok a múltból, Budapest, Athenaeum, s. d. [1930], p. 258 ; Károly Vörös, Budapest legnagyobb adófizetói 1873-1917, Budapest, Akadémiai Kiadó, 1979, p. 62 ; Kinga Frojimovics et al., A zsidó Budapest. Emlékek, szertartások, történelem, Budapest, Városháza/MTA Judaisztikai Kutatócsoport, 1995. 2 vol., t. 2, p. 357 ; Árpád Tóth, Önszervezó polgárok. À pesti egyesületek társadalomtörténete a reformkorban, Budapest, L'Harmattan, 2005, p. 190, 205, 252.

81. Zs. Groszmann, « A pesti zsidó gyülekezet », art. cit., p. 148.

82. Árpád Zeller, A magyar egyházpolitika 1847-1894, Budapest, Boruth E. Könyvnyomdája, 1894, 2 vol., t. 1, p. 4-7.

83. Ibid., p. 4-5.

84. Ibid., p. 5-6.

85. Ákos Birányi, Pesti forradalom. (Martius 15-18.), Pest, Nyomatott Trattner Károlynál, 1848, p. 38-39.

86. Jenő Zsoldos, 1848-1849 a magyar zsidóság életében [1948], Budapest, Múlt és Jövő, 1998, p. 62-64. 
acquise, les Juifs hongrois devant désormais « se fondre, en tant que citoyens vertueux, dans l'ensemble de la population ${ }^{87}$.

Le matin du 18 mars, Kunewalder faisait partie de la délégation pestoise, qui, au milieu des acclamations de la foule, partit en bateau à vapeur à Pozsony pour présenter les 12 points devant la diète ${ }^{88}$. Et c'est là que tout bascule ! La délégation arriva à Pozsony le 19 , le premier jour d'émeutes anti-juives qui transformèrent pendant trois jours la ville en champ de bataille ${ }^{89}$. Le 21 mars, jour fatidique, la diète exclut au dernier moment les Juifs du droit de vote dans les villes royales libres ; Lajos Kossuth, le leader de la révolution, dit compatir au sort des Juifs, mais déclara qu'il était des préjugés contre lesquels « même les dieux luttent en vain »; enfin, un projet de loi rédigé à la hâte, d'inspiration peu libérale, confia au futur gouvernement hongrois la tâche de présenter devant la prochaine réunion de la diète une loi sur la réforme de la religion juive ${ }^{90}$.

Kunewalder quitta Pozsony le jour même et rentra à Pest. Dès le lendemain, à titre privé cette fois, il publia une lettre ouverte aux « Hongrois de religion mosaïque », dans laquelle il les appelait, « considérant l'état actuel des choses », à entreprendre « les réformes les plus radicales ${ }^{91}$. Il ne s'étendit pas davantage sur le sujet, mais il semble qu'il songeait à des mesures du type de celles prônées par les mouvements réformistes radicaux qui essaimèrent à ce moment-là en Hongrie, comme de fêter le shabbat le dimanche ${ }^{92}$.

Il s'avéra cependant que les autres membres de la direction de la communauté de Pest ne voulaient pas entendre parler de telles réformes. Ils se désolidarisèrent officiellement de la position de leur président lors d'une réunion tenue le 26 mars, la dernière à laquelle assista Kunewalder ${ }^{93}$. Le 31 mars, la diète vota une loi sur l'égalité des religions dont la religion juive était exclue. À un député qui demanda ce qui allait advenir des Juifs, Lajos Kossuth, affirma que compte tenu des émeutes contre les Juifs, une loi d'émancipation ne ferait qu'attiser la vindicte populaire et répéta ce qu'il avait dit quelques jours plus tôt : «Il est des obstacles contre lesquels, parfois, même les dieux ne peuvent lutter ${ }^{94}$. » Enfin, le 3 avril, dans une lettre adressée au président de la communauté juive de Pest, c'est-àdire à Kunewalder, le Comité National Ministériel Provisoire annonça officiellement que l'émancipation était remise à plus tard ${ }^{95}$. Le 6 avril, quelques jours après avoir écrit à un ami juif, médecin de province, qu'il entendait continuer à œuvrer pour l'amélioration de la condition de ses coreligionnaires ${ }^{96}$, Kunewalder se convertit au catholicisme avec toute sa famille $^{97}$. Que la cause de sa conversion fut le désespoir, cela ne fait pas de doute. Qu'il ait désespéré avant tout des Hongrois qui lui refusaient une émancipation qu'il estimait lui être personnellement due, ou de ses coreligionnaires, qui en refusant les réformes radicales, sonnèrent selon lui le glas de ses espoirs de devenir, en tant que Juif, un citoyen égal à tous les autres, cette question reste ouverte.

87. Ibid., p. 64.

88. Á. Birányi, Pesti forradalom, op. cit., p. 54.

89. Les émeutes furent déclenchées par la bourgeoisie allemande sous prétexte de son opposition à l'entrée des Juifs dans la garde nationale. Gy. Haraszti, « Az 1848. évi magyarországi zsidóösszeírás », art. cit., p. 206.

90. « Pozsony, márt. 21-én », Pesti Hírlap, 24 mars 1847, p. 251-251.

91. J. Zsoldos, 1848-1849 a magyar zsidóság életében, op. cit., p. 76.

92. « Pest, ápril 7-én », Pesti Hírlap, 8 avril 1848, p. 309.

93. Zs. Groszmann, « A pesti zsidó gyülekezet », art. cit., 149-150.

94. « Országgyúlés », Pesti Hírlap, 7 avril 1848, p. 305.

95. S. Büchler, A zsidók története Budapesten, op. cit., p. 450.

96. József Bergl, A magyarországi zsidók története, Kaposvárott, Nyomatott Jeiteles Hermannál, 1879, p. 88.

97. J. Zsoldos, 1848-1849 a magyar zsidóság életében, op. cit., p. 285. 


\section{Conclusion}

Ces quatre hommes dont nous venons de tracer un bref portrait ne surgirent pas ex nihilo. Ils partageaient l'expérience de cette mince couche de la société juive, hommes d'affaires et intellectuels, dont tous les membres étaient en butte à une contradiction : d'une part, ils étaient les membres largement acculturés d'une société juive encore très largement traditionnelle, composant ainsi une étrange nouvelle élite juive flottant dans le vide ; ils étaient d'autre part résolument engagés dans une logique d'intégration dans une société hongroise qui leur promit l'égalité des droits, mais se révéla incapable de la leur offrir.

Un certain nombre de ces Juifs choisit de résoudre cette contradiction en abandonnant la religion juive. Leurs décisions étaient ancrées dans leur époque, et pour partie étroitement liées à leur époque. Si, un demi-siècle plus tard, il arrivait aux banquiers et capitaines d'industrie juifs d'accepter, voire de souhaiter, la conversion de leur fille pour peu qu'elle ouvrit la voie à un mariage aristocratique, eux-mêmes n'eurent plus à se convertir pour réaliser leurs ambitions entrepreneuriales et mener des carrières foudroyantes - et de fait, ils le firent rarement. Si l'époque de la Double Monarchie vit nombre d'intellectuels se convertir pour obtenir une nomination dans un lycée ou à l'université, ou simplement pour se débarrasser d'un fardeau social estimé inutile, aucun d'eux ne le fit parce qu'il perdait espoir de voir ses coreligionnaires s'engager sur la voie d'une acculturation alors déjà largement accomplie. On ne verra enfin à l'époque dualiste aucun dirigeant d'une grande communauté se convertir du jour au lendemain, pour quelque raison que ce fût. La période du Vormärz, et plus largement les quatre décennies précédant l'émancipation des Juifs en 1867, doivent ainsi être considérées comme une période distincte de l'histoire des conversions juives en Hongrie à l'ère moderne.

INSTITUT D'HISTOIRE DU CENTRE DE RECHERCHES EN SCIENCES HUMAINES DE L'ACADÉMIE DES SCIENCES DE HONGRIE 